\title{
ОБОГАЩЕНИЕ СРЕДЫ ДЛЯ СЕМЕЙСТВА МЕДВЕЖЬИ В ПАРКЕ «РОЕВ РУЧЕЙ»
}

\author{
I.Yu. Buyanov, M.M. Shulakova, \\ T.N. Tretinnikova, E.O. Nekipelova
}

\section{THE ENRICHMENT OF THE ENVIRONMENT FOR THE BEAR FAMILY IN THE PARK 'ROEV RUCHEY'}

Буянов Иван Юрьевич - канд. с.-х. наук, ст. науч. сотр. Парка фрлоры и фауны «Роев ручей», г. Красноярск.

E-mail: tiger-ra@yandex.ru

Шушакова Маргарита Михайловна - зав. отделом млекопитающих Парка фрлоры и фрауны «Роев ручей», г. Красноярск.

E-mail: ritik-75@mail.ru

Третинникова Татьяна Николаевна - зоолог II категории Парка фрлоры и фауны «Роев ручей», г. Красноярск.

E-mail: tretinnikovatanya@mail.ru

Некипелова Елена Олеговна - науч. сотр. Парка фрлоры и фауны «Роев ручей», г. Красноярск.

E-mail: nekipelova73@mail.ru

Цель исследования - применение категорий обогащения как отдельно, так и в сочетании, для увеличения двигательной активности и возможности реализации естественного поведения медведей. Материал собирался в г. Красноярске в Парке «Роев ручей». Использовались следующие категории обогащения: кормовое, предметное, визуальное, звуковое, запаховое, социальное, когнитивное, тренине. За медведями велись фоновые наблюдения и круглосуточное видеонаблюдение. Заполнялись журналы наблюдений, проводился первичный анализ заинтересованности зверей на проведенные действия. В качестве предметного обогащения парка использовались пластмассовые бочки, игрушки (шары, конусы), шины и стволы деревьев, свежие ветки хвойных деревьев. Игрушки использовались медведями по настроению, их заинтересованность зависела от новизны предмета. Визуальное обогащение среды медведей выражалось в возможности наблюдать других медведей и осматривать окрестности парка с возвышен-
Buyanov Ivan Yuryevich - Cand. Agr. Sci., Senior Staff Scientist, Park of Flora and Fauna "Roev Ruchey", Krasnoyarsk.

E-mail: tiger-ra@yandex.ru

Shushakova Margarita Mikhaylovna - Head, Department of Mammals, Park of Flora and Fauna "Roev Ruchey", Krasnoyarsk.

E-mail: ritik-75@mail.ru

Tretinnikova Tatyana Nikolaevna - Zoologist of II Category, Park of Flora and Fauna "Roev Ruchey", Krasnoyarsk.

E-mail: tretinnikovatanya@mail.ru

Nekipelova Elena Olegovna - Staff Scientist, Park of Flora and Fauna "Roev Ruchey", Krasnoyarsk.

E-mail: nekipelova73@mail.ru

ностей, расположенных в вольере. Для социального обогащения была сформирована пара бельх медведей, во взаимоотношении друг с другом проявляющая социальное взаимодействие, которое происходит не только во время брачного сезона, но и кругльй год. Реакция медведей на кормовое обогащение происходила всегда, у некоторых особей с задержкой во времени. С помощью тренингов возможно частичное либо полное избавление от приобретенных вредных привычек (стереотипии) $и$ страхов (боязнь помещений перегонки, шума крупной техники, большого скопления народа). Чем чаще происходил тренинг с животным (частота зависит от настроения и желания животного), тем спокойней и активней они общались с посетителями. Интерес к запаховому обогащению проявлялся периодически. При обогащении среды для животных в зоопарках должны учитьваться индивидуальные предпочтения каждой особи. Комбинированнье методы обогащения среды, такие как запаховое + предметное, кормовое + предметное, 
кормовое + запаховое, вызывают больший интерес у животных, чем «чистые» методы.

Ключевье слова: медведи, обогащение среды, категории обогащения.

The research objective was application of categories of enrichment both separately, and combining in order to increase physical activity and the possibility of realization of bears' natural behavior. The data was obtained in Krasnoyarsk Park "Roev ruchey". The following categories of enrichment were used: fodder, subject, visual, sound, smell, social, cognitive and training. For bears background supervision and round-the-clock video surveillance were performed. The magazines of supervision were filled; primary analysis of interest of animals to performed actions was made. As the subject of the enrichment park plastic barrels, toys (spheres, cones), tires and trunks of trees, fresh branches of coniferous trees were used. The toys were used by bears according to the mood; their interest depended on the novelty of a subject. Visual enrichment of the circle of bears was expressed in the opportunity to observe other bears and to examine park vicinities from the heights located in the openair cage. For social enrichment a couple of polar bears, in relationship with each other showing social interaction which happens not only during marriage season, but also all the year round was created. The reaction of bears to fodder enrichment always took place, at some individuals to a time lag. By means of training perhaps partial or full disposal of acquired addictions (stereotypes) and fears (of rooms of distillation, the noise of large equipment, big congestion of the people) were got rid of. The oftener there was animals' training (the frequency depends on mood and desire of an animal), the more quietly and more actively they communicated with visitors. The interest in smell enrichment was periodically shown. At the enrichment of the environment for the animals in the zoos individual preferences of each individual have to be taken into consideration. Combined methods of the environment enrichment, such as smell + subject, fodder + subject, fodder + smell, cause more interest in animals, than "pure" methods.
Keywords: bears, environment enrichment, enrichment categories.

Введение. Обогащение среды как способ повышения благополучия животных, живущих в зоопарках, используется давно. Для того чтобы понять, удовлетворяются ли поведенческие потребности животных обогащением среды, нужно постоянно поддерживать заинтересованность животных, проживающих в парке, применяя новые способы обогащения среды. В основном используются следующие категории обогащения: кормовое, предметное, визуальное, звуковое, запаховое, социальное, когнитивное, тренинг [5]. Категории применяют как отдельно, так и сочетая меж собой.

Цели исследования: применение категорий обогащения как отдельно, так и в сочетании, для увеличения двигательной активности и возможности реализации естественного поведения медведей.

Задача исследования: мониторинг реакции зверей при применении различных способов обогащения среды.

Материалы и методы исследования. Материал собирался в г. Красноярске в Парке «Роев ручей». За медведями ведутся фоновые наблюдения и круглосуточное видеонаблюдение. Согласно утвержденному плану обогащения среды, заполняются журналы наблюдений, зоологами проводится первичный анализ заинтересованности зверей на проведенные действия.

Медведи в парке содержатся на открытом воздухе, разные виды медведей совершенно по-разному переносят температурные диапазоны среды. Самый широкий диапазон с морозным, умеренным и теплым периодом имеют бурые медведи. У белого медведя большая часть его кривой выносливости лежит в области отрицательных температур. Белый медведь - от -40 до $+10{ }^{\circ} \mathrm{C}$, бурый медведь - от -15 до $+30{ }^{\circ} \mathrm{C}$, гималайский медведь - от - 10 до $+20^{\circ} \mathrm{C}$ [2].

При некомфортных условиях животные имеют возможность укрыться в построенных для них укрытиях либо охладиться в бассейнах. При солнечной жаркой погоде дополнительно увлажняется вольер и поливается животное. 
Медведи прекрасно приспосабливаются к большим колебаниям влажности и содержатся при естественной смене дня и ночи. Имеется искусственное освещение в вечернее и ночное время суток. Звери наиболее адаптивны к антропогенным факторам. Реакцию стресса могут вызвать внезапные шумы. Быстро привыкают к постоянному фоновому шуму.

Звери содержатся по одиночке, только белые медведи по кличке Феликс и Аврора живут в одном вольере совместно разнополой парой.

Результаты исследования и их обсуждение. В качестве предметного обогащения зоологами парка используются пластмассовые бочки, игрушки (шары, конусы), шины и стволы де- ревьев, свежие ветки хвойных деревьев, которые оставляются в вольере на весь период обогащения. В вольерах построены бассейны и имеются «купалки» для удовлетворения естественной потребности животных в воде (рис. 1). В летнее время туда запускается живая рыба. Оборудованы берлоги. Постоянная экспозиция декорирована природными материалами - древесиной. В экспозицию помещаются пни, стволы деревьев с отверстиями, в которые прячется корм. Устроены приподнятые деревянные полки. Во всех вольерах бетонный пол. Периодически работниками парка вносятся следующие субстраты: опилки, кора, ветки [4].

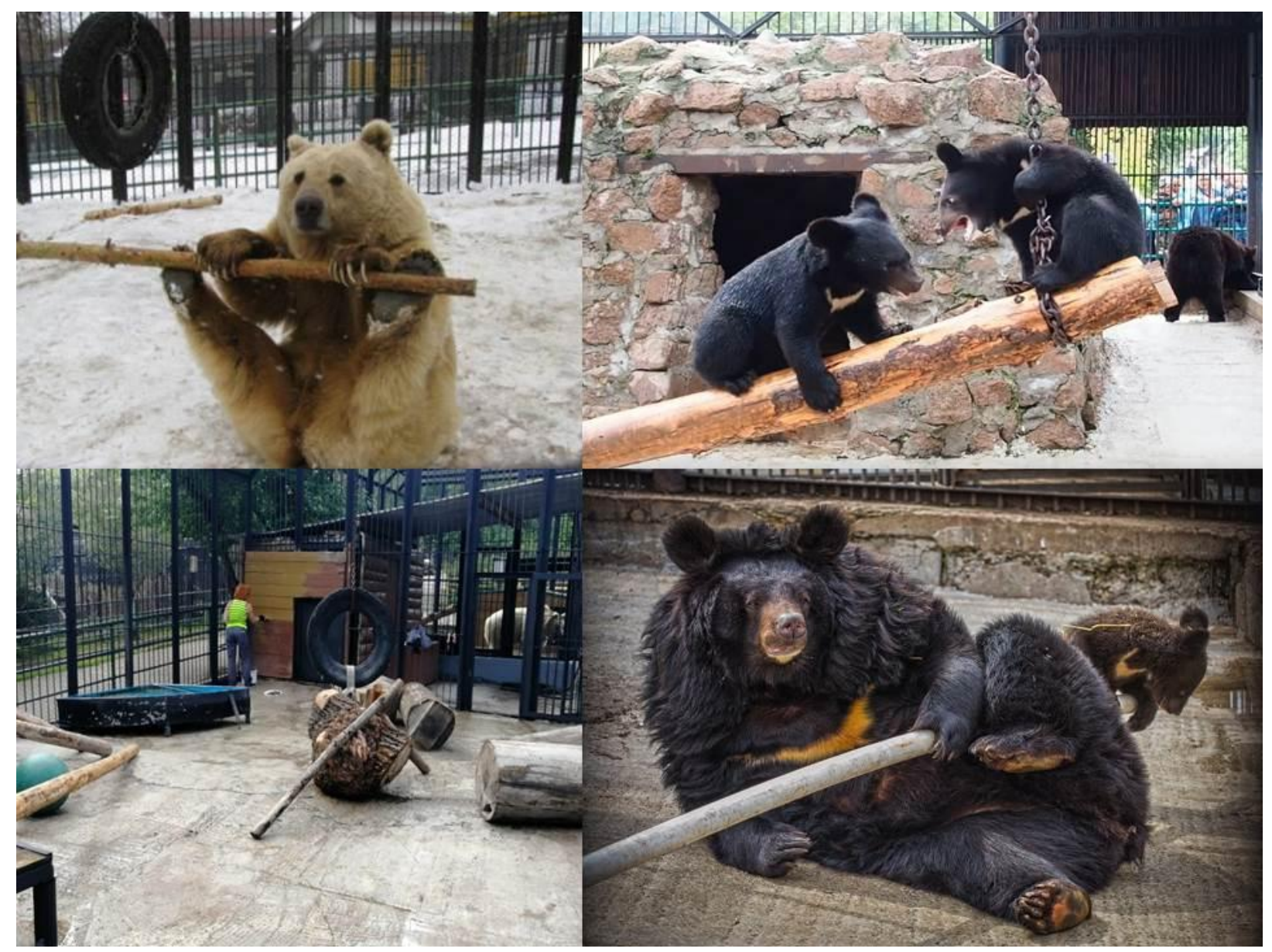

Puc. 1. Предметное обогащение естественными древесными стволами и пнями, свободно подвешенными стволами. Игрушка «жердь» 
В качестве кормового обогащения зоологами применяется внесение живого корма и укрытие корма в сложные конструкции для его извлечения. Замороженные в лед овощи и фрукты особенно в летнее время - отличный способ держать медведей в активном состоянии. Брошенные в бассейн куски льда с фрруктами или овощами внутри занимают животных на некоторое время (рис. 2).
Свежая трава, ветки с листвой, плоды растений, помещенные в вольер работниками парка, особенно весной после спячки и в летнее время благотворно влияют на зверей. Содержащееся в растительной пище сырое волокно стабилизирует работу желудочно-кишечного тракта и способствует пищеварению, а также обеспечивает организм различными ценными компонентами, такими как белки, витамины и минералы [1].

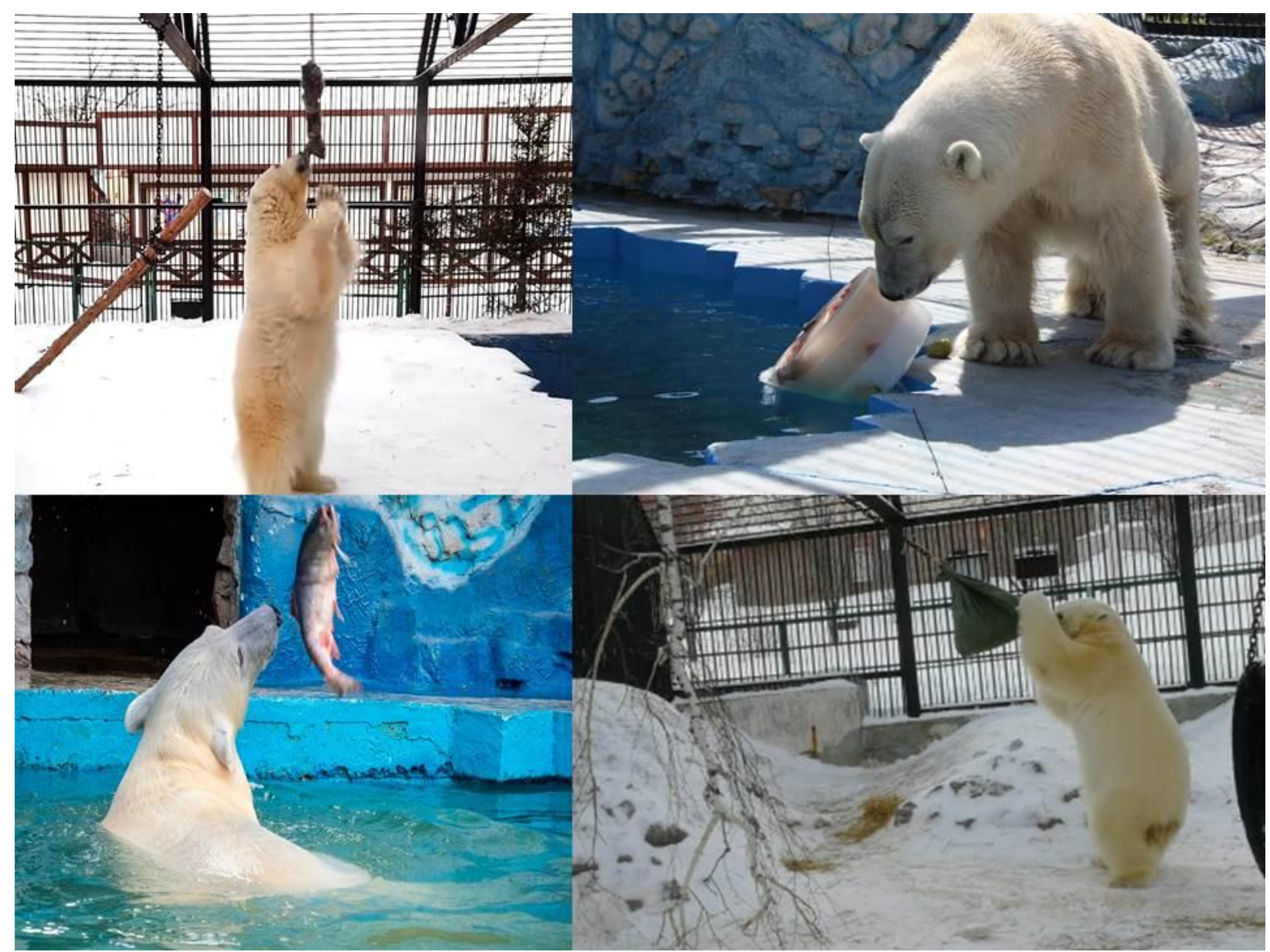

Puс. 2. Предметное и кормовое обогащение

Зимой бассейны стоят сухие, в них помещается солома, в которой белые медведи с удовольствием играют и спят (рис. 3).

Пластиковые цилиндры и шары с запаховыми и звуковыми капсулами изготовила группа компаний «ТехПолимер» по спецзаказу АНО «Общество дикой природы» (при поддержке ПАО «НК «Роснефрть») для обогащения среды обитания белых медведей. Игрушки представляют из себя большие цилиндры и средних размеров шары с отверстиями и потайными капсулами, в которые зоологи закладывают корм, части ароматных растений (рис. 4).

Занятость медведей игрушками по времени разнится [3]. Время занятости Урсулы предметами составило более 5 ч в сутки, это связано с 
положительной адаптацией к условиям зоопарка и молодым возрастом (2 года). Занятость предметами Феликса составила 1,5 ч, это связано с более старшим возрастом (14 лет) и суточной активностью, Авроры - 2 ч, так как ей 10 лет и суточная активность больше, чем у Феликса. Занятость Марфы составляет около 1 ч, малое количество времени связано с небольшим сроком проживания (8 месяцев) на территории парка и постепенной адаптацией к его условиям. Гималайские медведи (двое медвежат) затрачивают около 3 ч, так как молоды и им все интересно, а самка Аза тратит около 30 мин, что связано с ее большим возрастом (19 лет), бурые медведи также преклонного возраста - Маша (26 лет), Буян (20 лет), их занятость предметами - около 30 мин. Возраст белокоготного бурого медведя 14 лет, и его занятость игрушками может составлять около 1 ч (табл. 1).

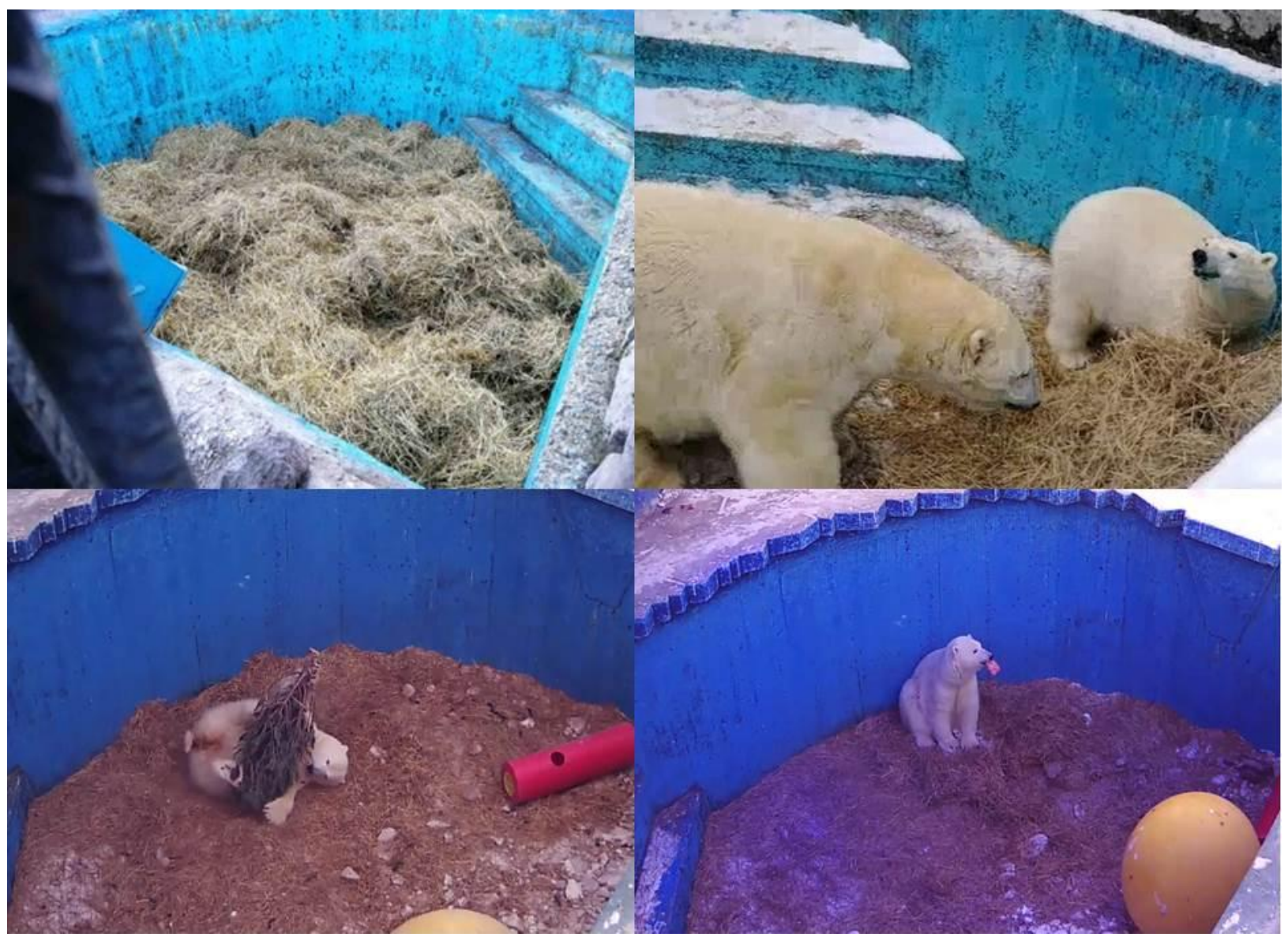

Рис. 3. Медведи в сухом бассейне (субстрат солома) 
Занятность медведей предметами (игрушками)(проявление интереса)

Таблица 1

\begin{tabular}{|c|c|c|c|c|c|c|c|c|c|c|}
\hline $\begin{array}{l}\text { Предмет } \\
\text { (игрушка) }\end{array}$ & \multicolumn{4}{|c|}{ Белые медведи } & \multicolumn{3}{|c|}{ Гималайские медведи } & \multicolumn{2}{|c|}{ Бурые медведи } & $\begin{array}{c}\begin{array}{c}\text { Белокоготный бурый } \\
\text { медведь }\end{array} \\
\text { Памир }\end{array}$ \\
\hline Мяч & + & + & + & + & - & - & - & - & - & - \\
\hline Цилиндр & + & + & + & + & - & - & - & - & - & - \\
\hline Шар & $+/-$ & $+/-$ & $+/-$ & $+/-$ & + & + & + & + & + & + \\
\hline Куб & $+1-$ & $+/-$ & $+/-$ & $+/-$ & - & - & - & - & - & - \\
\hline Жердь & + & - & + & - & + & + & + & + & + & + \\
\hline Шкура & + & + & + & + & - & - & - & - & - & - \\
\hline Пожарный рукав & + & + & + & + & - & - & - & - & - & + \\
\hline Шина & + & + & + & + & + & + & + & + & + & + \\
\hline
\end{tabular}




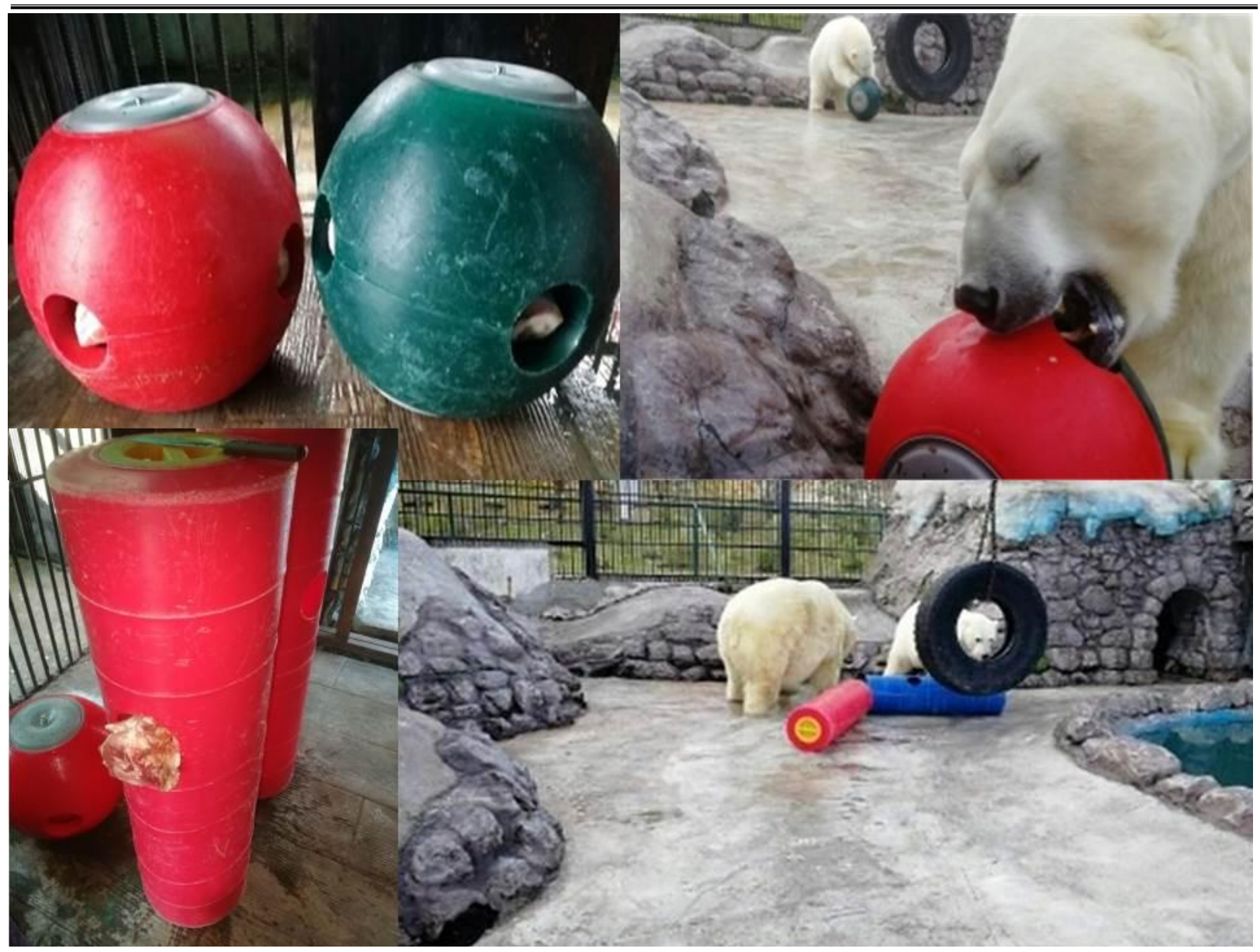

Pис. 4. Пластиковый кормовой цилиндр, мяч. Удовлетворение потребности в охоте

Для запахового обогащения среды используются не только инородные и нетипичные запахи, но также территориальные маркировки других медведей или иных животных, которые очень интересны и вносят значительное разнообразие в повседневную жизнь. Зоологи стимулируют активность медведей с помощью необычных специй, запаха рыбьего жира и разнообразной подстилки и веников древесных растений.

Социальное и визуальное обогащение среды. В парке есть сформированная пара белых медведей, которая во взаимоотношении друг с другом проявляет социальное взаимодействие, что очень важно в повседневной жизни зверей. Социальное взаимодействие пары медведей происходит не только во время брачного сезона, но и круглый год.

Визуальное обогащение среды медведей выражается в возможности наблюдать других медведей и осматривать окрестности парка с возвышенностей, расположенных в вольере. Есть доступ в вольер свободно живущих птиц: сорок и ворон.

Комбинированные методы обогащения среды, такие как запаховое + предметное, кормовое + предметное, кормовое + запаховое, вызывают больший интерес у животных, чем «чистые» методы.

Тренинг животных давно активно используется в работе зоопарков. Тренинг является также одним из способов обогащения среды для животных, обогащает их ментально, при этом важно, чтобы действия животных были бы добровольными (рис. 6). Практическое значение тренинга составляют способы и приемы воздействия на животных с целью воспроизведения и закрепления той или иной реакции для ветеринарного осмотра (показ лап, спины, живота, зубов). 
Вестник КрасТАУ. 2020. № 3

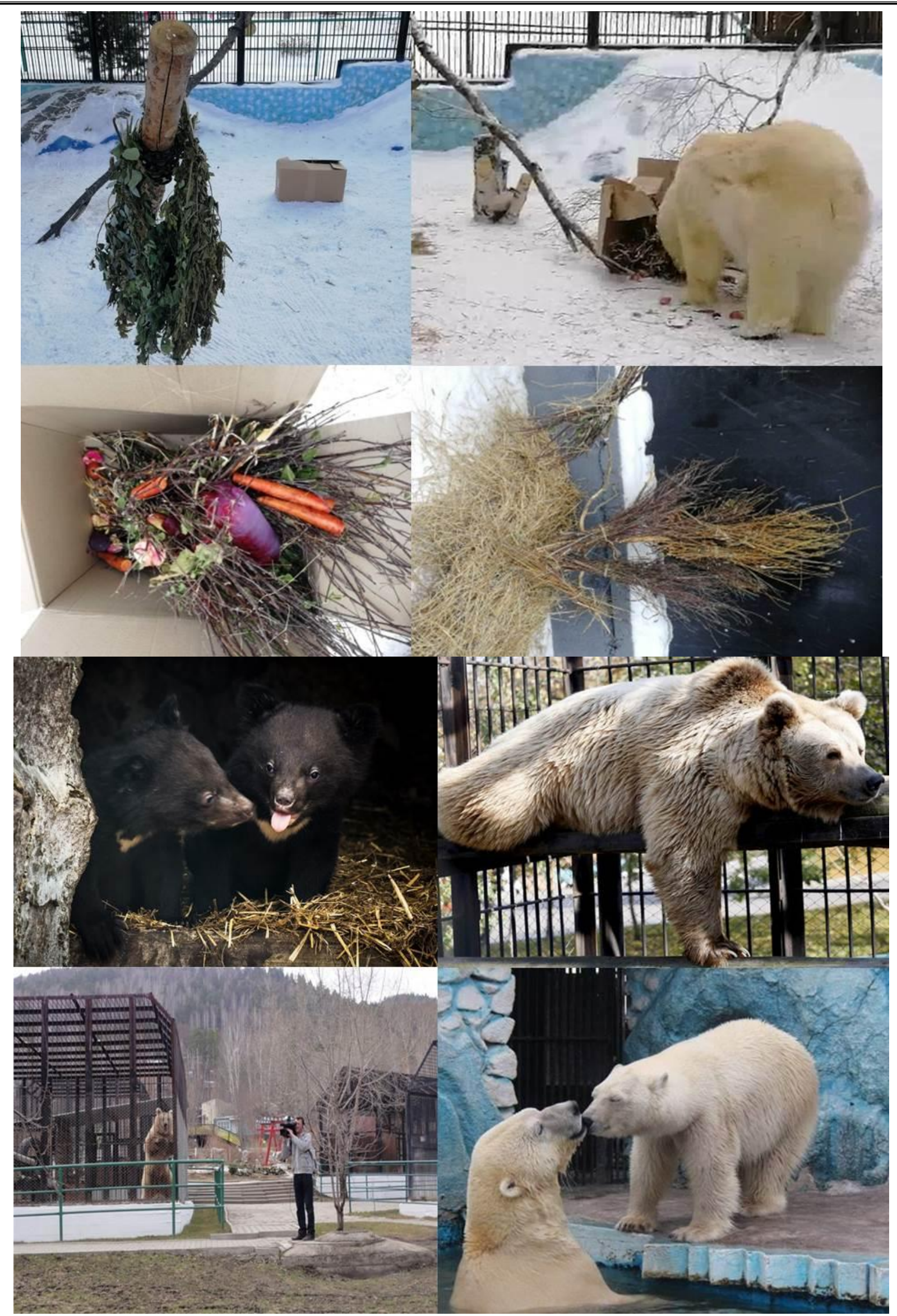

Puс. 5. Запаховое, социальное и визуальное обогащение среды медведей 


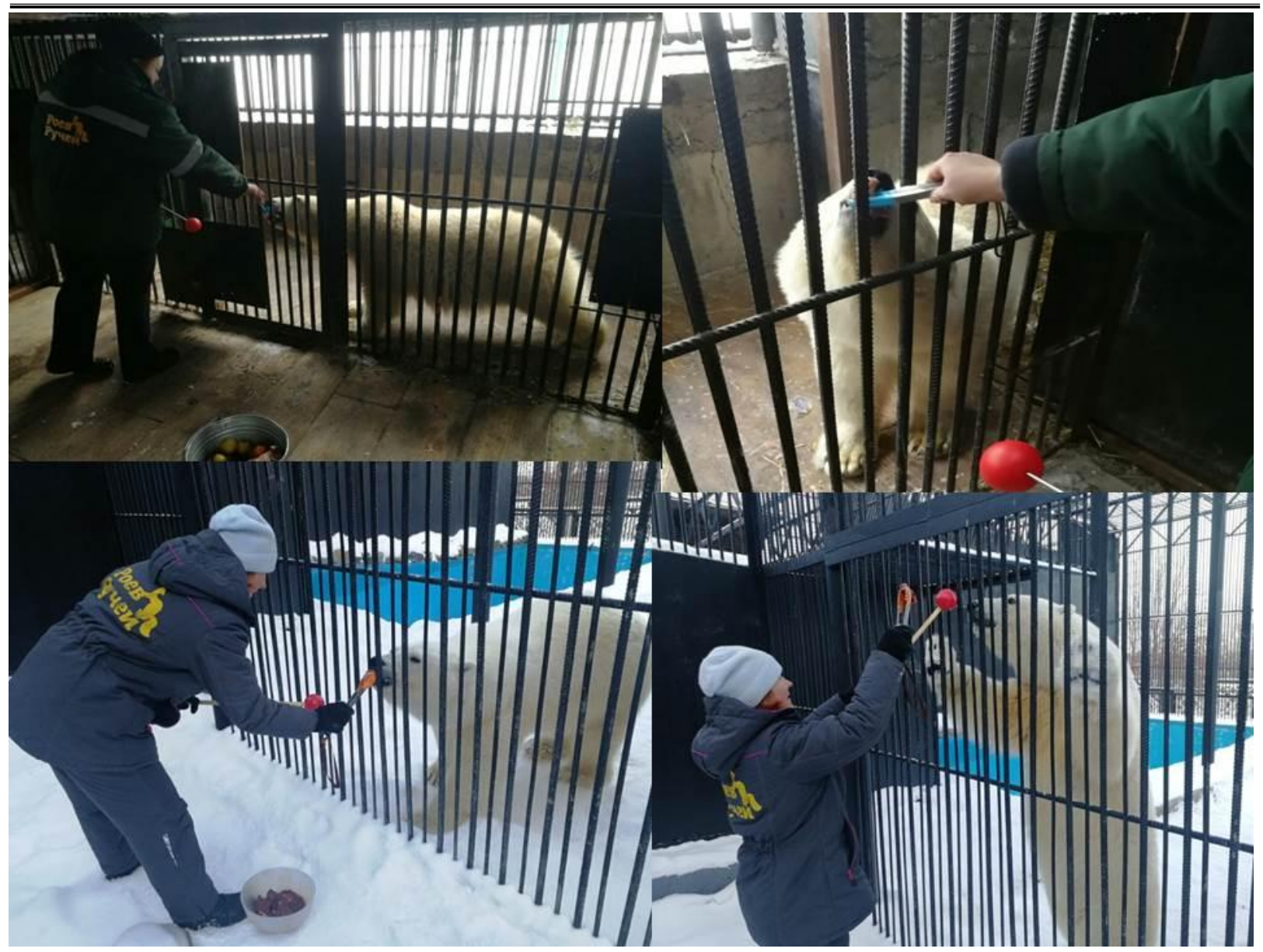

Pис. 6. Тренинг с бельм медведем

Данные, полученные в парке, свидетельствуют о том, что чем чаще происходит общение (ежедневно) с животными, тем более спокойно и активно они общаются с посетителями. А также избавляются от приобретенных вредных привычек и страхов. Медведицу по кличке Урсула за семь месяцев тренинга избавили от боязни «перегонки». Еженедельное проведение тренинга с медведицей Марфой кратковременно снижает уровень стресса данной особи.

\section{Выводы}

1. При обогащении среды для животных в зоопарках должны учитываться индивидуальные предпочтения каждой особи. Реакция медведей на кормовое обогащение происходит всегда, у некоторых особей с задержкой во времени. Игрушки (предметное обогащение) используются медведями по настроению, их заинтересованность зависит от новизны предмета. Интерес к запаховому обогащению проявляется пе- риодически. Комбинированные методы обогащения вызывают более активную реакцию, чем «чистые» методы.

2. Чем чаще происходит тренинг с животным (частота зависит от настроения и желания животного), тем более спокойно и активно они общаются с посетителями. А также с помощью тренингов возможно частичное либо полное избавление от приобретенных вредных привычек (стереотипии) и страхов (боязнь помещений перегонки, шума крупной техники, большого скопления народа).

\section{Литература}

1. Броновец И.Н. Пищевые волокна - важная составляющая сбалансированного здорового питания // Медицинские новости. 2015. №10. C. 46-48.

2. Емельянов А.В. Животные зооботанического сада ТГУ. Бурый медведь / сост. А.В. Емельянов, Н.А. Чернова, А.А. Гусев 
[и др.]; Тамб. гос. ун-т им. Г. Р. Державина. Тамбов, 2007. 44 c.

3. Некипелова Е.О., Буянов И.Ю., Шушакова М.М. и др. Адаптация белых медведей к условиям парка «Роев ручей» // Вестник КрасГАУ. 2020. № 1. С. 84-89.

4. Попов С.В. Рекомендации по обогащению среды при содержании животных в неволе. M., 2003.

5. Mellor D. J., Hunt S. \& Gusset M. (eds) (2015) Caring for Wildlife: The World Zoo and Aquarium Animal Welfare Strategy. Gland: WAZA Executive Office, $87 \mathrm{pp}$.

\section{Literatura}

1. Bronovec I.N. Pishhevye volokna - vazhnaja sostavljajushhaja sbalansirovannogo zdorovo- go pitanija // Medicinskie novosti. 2015. № 10. S. 46-48.

2. Emel'janov A.V. Zhivotnye zoobotanicheskogo sada TGU. Buryj medved' / sost. A.V. Emel'janov, N.A. Chernova [i dr.]; Tamb. gos. un-t im. G. R. Derzhavina. Tambov, 2007. $44 \mathrm{~s}$.

3. Nekipelova E.O., Bujanov I.Ju., Shushakova M.M. i dr. Adaptacija belyh medvedej k uslovijam parka «Roev ruchej» // Vestnik KrasGAU. 2020. № 1. S. 84-89.

4. Popov S.V. Rekomendacii po obogashheniju sredy pri soderzhanii zhivotnyh $v$ nevole. M., 2003.

5. Mellor D. J., Hunt S. \& Gusset M. (eds) (2015) Caring for Wildlife: The World Zoo and Aquarium Animal Welfare Strategy. Gland: WAZA Executive Office, $87 \mathrm{pp}$. 